\title{
Deep lamellar endothelial keratoplasty (DLEK): pursuing the ideal goals of endothelial replacement
}

\begin{abstract}
Endothelial dysfunction is a leading cause of corneal vision loss and treatment requires surgical replacement with donor endothelium. Standard penetrating keratoplasty (PK) suffers from the inherent problems of surface corneal incisions and sutures and poor wound healing of vertical stromal wounds. This often results in high irregular astigmatism, unpredictable corneal power, and the risk of long-term visual loss from suture-induced vascularization, ulceration, rejection, and late wound rupture. This paper delineates five ideal goals of endothelial replacement, which include: (1) a smooth surface topography without significant change in astigmatism from preoperative to postoperative; (2) a highly predictable and stable corneal power; (3) a healthy donor endothelium that resolves all oedema; (4) a tectonically stable globe, safe from injury and infection; and (5) an optically pure cornea. Deep lamellar endothelial keratoplasty (DLEK) is a surgical method of endothelial replacement that is performed through a limbal scleral incision that leaves the surface of the recipient cornea untouched. The early results of this innovative surgery are discussed and compared to the results of PK in terms of fulfillment of the five ideal goals of endothelial replacement. With further refinement of interface creation, DLEK surgery may be the ideal method for endothelial replacement.

Eye (2003) 17, 982-988. doi:10.1038/

sj.eye.6700614
\end{abstract}

Keywords: cornea; endothelium; DLEK; PK; lamellar keratoplasty; Fuchs' dystrophy

\section{Introduction}

There are approximately 38000 corneal transplants performed in the United States each year and nearly half of all of these grafts are done for visual loss because of endothelial dysfunction. ${ }^{1}$ The only surgical technique for endothelial replacement for over 80 years has been a full-thickness penetrating keratoplasty (PK). ${ }^{2}$ Although advances in technology and technique of both surgery and eye banking have improved the success rate of clear grafts after transplant surgery, PK incurs significant liabilities in wound healing and optics for the transplant patient. ${ }^{1,3}$ The vertical stromal wound of PK results in delayed wound healing that not only creates unpredictable and shifting refractive error, but also exposes the patient to the significant risk of late incision rupture and loss of the eye..$^{4-9}$ Despite the myriad ingenious suturing techniques described in the literature for PK, the sutures of PK continue to be a source of infection, ulceration, vascularization, rejection, and unpredictable astigmatism of varying magnitude. ${ }^{10-22}$

The major drawbacks of PK can be traced to the inherent problems of surface corneal sutures and a vertical stromal wound. If corneal sutures could be eliminated and the vertical stromal wound minimized, then many of the problems with PK would also be eliminated. Recent advances in posterior lamellar surgery have allowed for the replacement of the endothelium while leaving the surface of the cornea untouched. ${ }^{23-31}$ Results with this innovative technique are encouraging and promise a new level of expectations for success by the corneal transplant patient.

The ideal goals of endothelial replacement In the past, the goal of PK for endothelial replacement was simply to transfer enough healthy endothelium so that the graft would be clear with only moderate astigmatism. The significant risks of suture-induced astigmatism,
Received: 28 February 2003 28 February 2003 
vascularization, infection, and unpredictable corneal power were felt to be inherent and largely unavoidable. The risk of nontraumatic, spontaneous wound dehiscence after suture removal has been reported as $\geq 7.2 \%$, and this too was felt to be unavoidable. ${ }^{4}$ With the advent of lamellar surgery for endothelial replacement, the goals of surgery need to be reassessed and surgeons need to question their traditional criteria for success. ${ }^{30}$

The surgeon who replaces the endothelium should strive to provide a procedure that not only restores vision, but also minimizes or eliminates the problems associated with that restoration. In the past, corneal transplantation was considered a success if the corneal endothelium survived and the graft remained clear, even if the patient had to wear rigid contact lenses to achieve useful vision. As surgical techniques advanced, success was defined as a clear graft with minimal astigmatism, obviating the need for contact lenses. As new surgical strategies for corneal transplantation have arrived, the goals of the surgeon should also be raised and reassessed. A clear transplant with even moderate astigmatism may yield a vision of $20 / 20$, but if that same graft succumbs to ulceration or infection because of retained sutures or, worse yet, ruptures at the wound years later because of mild blunt trauma with loss of the eye, then this transient result of 20/20 can hardly be termed a true 'success'. ${ }^{4-9}$

Any procedure that replaces the endothelium should ideally incorporate the following ideal goals for the postoperative eye: (1) a smooth surface topography without significant change in astigmatism from preoperative to post-operative; (2) a highly predictable and stable corneal power; (3) a healthy donor endothelium that resolves all oedema; (4) a tectonically stable globe, safe from injury and infection; and (5) an optically pure cornea. The success of any transplant procedure should be measured not just by Snellen visual acuity, but also by the extent to which the procedure fulfils the ideal goals of corneal transplantation. ${ }^{30}$ This paper will review the current surgical strategies for endothelial transplantation in the context of fulfillment of these ideal goals, and detail the new surgical technique of deep lamellar endothelial keratoplasty (DLEK) that may improve our ability to attain an ideal anatomic and visual result.

\section{Lamellar surgery for endothelial replacement}

The philosophy of lamellar keratoplasty (LK) is to selectively replace only the diseased tissue and leave the healthy tissue intact, to resect the least amount of tissue for the greatest amount of good. ${ }^{30,32}$ LK has been successful in the treatment of anterior corneal pathology for over 100 years. ${ }^{33}$ Only recently have the techniques of
LK been applied to the replacement of the posterior tissue and the endothelium..$^{23-31}$ One lamellar technique for endothelial replacement involves the creation of a surface corneal flap with a microkeratome, followed by trephination of the recipient posterior tissue and replacement with a posterior donor button. In this technique, the donor tissue is either sutured into place and/or oversized, and the surface 'Lasik style' corneal flap is sutured down into position. This lamellar 'flap' technique has been investigated separately by several surgeons, including Culbertson, ${ }^{34}$ Busin and Arfa, ${ }^{35}$ Ehlers, ${ }^{36}$ Silk, $^{37}$ and Azar. ${ }^{38,39}$ Despite the technical appeal of this surgery, this surgical technique suffers from the same inherent problems seen in traditional PK of surface sutures and a vertical stromal wound. Complications such as a $21 \%$ primary graft failure rate, surface epithelial ingrowth, flap melt, unpredictable corneal power, and irregular astigmatism have plagued early reports. ${ }^{34-40}$ The results of this technique, therefore, have been largely disappointing in their fulfilment of the five goals of endothelial transplant surgery.

The technique of endothelial replacement through a superior scleral pocket wound was first described in animal work by Ko et $a l^{41}$ in 1993. This technique was critically modified by Gerrit Melles ${ }^{23}$ of the Netherlands with cadaver eye and primate work in 1997 and termed 'Posterior Lamellar Keratoplasty' (PLK). The first successful PLK in a human was performed by Melles ${ }^{25}$ and reported in 1999. His first series of patients with long-term follow-up was reported in $2000 .^{29}$ In 1999, Mark Terry and Paula Ousley of the United States began laboratory investigation of the PLK procedure, and after modification of the technique and instrumentation, they termed the procedure 'deep lamellar endothelial keratroplasty' (DLEK). They published their laboratory data in 2001 and the results from their first two clinical patients that same year. ${ }^{27,28}$ Terry's first clinical series of DLEK patients was published in 2003. ${ }^{30}$ Continued laboratory and clinical work in PLK/DLEK continues separately by Melles ${ }^{42,43}$ and by Terry ${ }^{44-46}$ with the evolution of this procedure still in progress.

\section{Deep lamellar endothelial keratoplasty}

In the DLEK technique, the preoperative corneal surface is left untouched in an attempt to preserve normal corneal topography. The corneal limbus is preserved to aid in the structural integrity of the globe, and to allow endothelial transfer in a relatively closed controlled system. The surgical steps are straightforward, but require specialized instrumentation. ${ }^{27,28,30,31,44-46}$

DLEK surgery begins with the creation of a $9.0 \mathrm{~mm}$ length scleral wound, created with a guarded diamond knife set at $350 \mu$ and located approximately 1-2 mm 
posterior to the superior corneal limbus. A sharp crescent blade is then utilized to create a deep scleral-corneal lamellar pocket down to about 75-85\% corneal depth along the entire length of the wound. A specialized semisharp stromal dissector is then used to extend the pocket to the mid-pupillary region of the cornea and then a curved stromal dissector (Devers Dissector) extends the pocket completely to the limbus for $360^{\circ}$, creating a total area, deep lamellar corneal pocket. A specialized intrastromal trephine (Terry Trephine) is then placed within the stromal pocket, and Healon viscoelastic is injected into the anterior chamber to provide backpressure for the trephination. The Terry Trephine is rotated back and forth along the arc length of the wound, creating a trephination cut of the posterior stroma that is easily visualized and the anterior chamber is entered. The trephine is removed, and then special low-profile intrastromal scissors (Cindy Scissors) are used to complete the trephination cut and resection of the recipient tissue. The recipient posterior disc is then removed, inspected for symmetry and smoothness of the interface, and then sent to pathology. Great care is then taken to completely remove all of the viscoelastic material in the anterior chamber using standard irrigation-aspiration techniques to allow for later donor attachment. The wound is closed with a single temporary safety suture and the microscope is turned to the donor table. The donor corneo-scleral tissue is then mounted into an artificial anterior chamber after the endothelium is coated with Healon. The anterior stromal tissue is then resected, removing all but the posterior $150 \mu$ of tissue. This has been done with manual resection instrumentation, but recently has been accomplished with the use of the microkeratome (Terry and Ousley, unpublished data). The donor tissue is removed from the artificial anterior chamber and mounted endothelial side up onto a standard donor punch trephine block. A standard donor punch trephine with the same diameter as that of the Terry Trephine is then used to punch out the donor tissue and the posterior donor disc is separated from the remaining donor tissue rim. The posterior donor disc is then placed endothelial side down onto a Healon-coated specialized insertion spatula (Ousley spatula) and brought into the recipient surgical field. The anterior chamber of the patient is then filled with air, the safety suture removed, and in one quick movement the Ousley spatula is inserted into the anterior chamber, levelled with the iris plane, raised anteriorly until the donor stromal surface and the recipient stromal bed surface coapt, and then the spatula is withdrawn from the eye on a layer of Healon leaving the donor tissue in place, supported by the air bubble in the anterior chamber and self-adhering without sutures. The tissue position is adjusted with a Sinskey hook, the superior scleral wound is closed with several interrupted sutures, and the air bubble is replaced with BSS and the pressure normalized. It is felt that the tissue initially self-adheres because of the normal physical hydrophilic attraction between wet tissues with air on both sides. When the air is replaced (about $15 \mathrm{~min}$ after donor placement), the adherence of donor disc is felt to be because of donor endothelial pump function creating a stromal suction adherence. The conjunctival peritomy is closed, antibiotics administered, and the eye patched.

The clinical results of DLEK surgery can be critically evaluated through their fulfillment of the ideal goals of endothelial replacement surgery.

\section{Surface topography and astigmatism}

The DLEK procedure largely allows retention of the smoothness and refractive amplitudes of the normal recipient corneal topography with the result of minimal refractive astigmatism. Melles' initial series of seven PLK patients averaged $1.54 \pm 0.81 \mathrm{D}$ of astigmatism and Terry's first series of eight DLEK patients averaged only $2.28 \pm 1.03 \mathrm{D}$ of astigmatism, representing an average change in astigmatism from the pre-op state of only $1.13 \pm 1.50$ D. ${ }^{30}$ In Terry's latest series of 21 consecutive DLEK patients who have reached the 6 months postoperative gate, the average astigmatism is $1.76 \pm 0.92 \mathrm{D}$, representing a mere $0.29 \mathrm{D}$ of change in refractive cylinder from the preoperative measurements. These DLEK results compare quite favourably to the 3-6 D of average refractive astigmatism seen after standard PK for Fuch's dystrophy, with over $42 \%$ of PK eyes with $\geq 5$ D of astigmatism, even in the best of hands. ${ }^{47}$ The smoothness and regularity of the corneal topography can be objectively measured with the TMS corneal mapping system, utilizing the software indices of surface regularity index (SRI) and surface asymmetry index (SAI). ${ }^{48}$ Normal SRI and SAI values are typically about 1.0 with the higher the index, the more irregular the surface astigmatism. In the first Terry and Ousley series, the average SRI was $0.94 \pm 0.18$ and the average SAI was $0.77 \pm 0.51 .^{30}$ In the latest series of 21 DLEK patients, the average SRI at 6 months post-op was $1.11 \pm 0.36$, and the average SAI was $0.96 \pm 0.90$. This was a significant improvement in surface smoothness from the irregular astigmatism from oedema seen preoperatively with values of $S R I=1.63 \pm 0.68$ and $S A I=1.92 \pm 1.46$. Most importantly, the DLEK procedure is found to be far superior to $\mathrm{PK}$ in restoring surface smoothness. In a report by Gross et al ${ }^{16}$ utilizing the same topographer technology in Fuch's patients after PK, the average SRI score was found to be highly irregular at 3.24 and the average SAI was also abnormal at 1.69. Clearly, the absence of corneal surface sutures or incisions with 
DLEK surgery largely fulfils the first goal of endothelial replacement surgery, while PK fails miserably at this challenge.

\section{Stable and predictable corneal power}

One of the most vexing problems in PK surgery is the unpredictability of the central corneal power as measured by keratometry and corneal mapping. This is especially a problem when performing the so-called 'triple procedure' of corneal transplantation, cataract surgery, and IOL placement. Accurate calculation of the IOL power is dependent upon knowing the final corneal keratometry readings. Unfortunately, before surgery is performed and despite the best nomograms, final PK keratometry readings are an educated guess at best, and the graft may result in steep or flat topography. It is, therefore, not unusual after PK to have a crystal-clear graft, yet $\geq 5 \mathrm{D}$ of induced myopia or hyperopia due to a mismatch between the final graft keratometry power and the power of the intraocular lens. Indeed, the range of corneal spherical equivalents after standard PK surgery have been reported as between -6.75 and +7.25 D. ${ }^{49,50}$ The resultant intolerable anisometropia can be a disappointment for patient and surgeon alike.

The DLEK procedure shows remarkable stability and preservation of the preoperative keratometry readings. In Terry's initial series, he reported an average change in keratometry reading (as measured by TMS-1 mapping) of only $0.40 \mathrm{D}$ from the preoperative measurements. ${ }^{30}$ In the most recent series of 21 patients at 6 months, the average keratometry reading was $43.8 \pm 1.3 \mathrm{D}$ compared to the preoperative measurement of $43.9 \pm 1.9$ D. Such preservation of corneal power and appropriate matching to the individual IOL power is reflected in the reduction of wide variation in the final refractive spherical equivalents seen after DLEK surgery. In the recent series of 21 consecutive DLEK patients by Terry and Ousley, the average spherical equivalent at 6 months is $-0.321 \pm 1.840 \mathrm{D}$. This is statistically insignificant from the spherical equivalent of $-0.25 \pm 2.25$ seen before DLEK surgery $(P \geq 0.8)$. Such predictability of post-transplant corneal power promises an expectation for near emmetropia in 'The New Triple Procedure' of DLEK surgery combined with cataract extraction and IOL placement. ${ }^{46}$

\section{Healthy donor endothelium}

The sine-qua-non of successful endothelial replacement surgery is the resolution of corneal oedema with a healthy donor endothelium. Traditional PK surgery has provided us with clear grafts and excellent post-op endothelial cell densities. Ing and Bourne have shown that Fuch's PK patients have an average cell count of $1958 \pm 718$ cells $/ \mathrm{mm}^{2}$ at 1 year, with progressive cell loss to a level of $960 \pm 470$ cells $/ \mathrm{mm}^{2}$ after 10 years. ${ }^{51,52}$ After endothelial replacement through PLK surgery, Melles has reported an average cell count of $2520 \pm 340$ cells $/ \mathrm{mm}^{2}$ and Terry reported similar results at 6 months for his initial series. ${ }^{29,30}$ The last consecutive 21 patients in Terry's DLEK study have an average endothelial cell density of $2193 \pm 456$ at 6 months $(n=21)$ and $2231 \pm 573$ at 1 year $(n=15)$. This represents only an average $19 \%$ cell loss from pre-operative cell counts and compares favourably with the $34 \pm 22 \%$ cell loss sustained by the PK patients at 1 year postoperatively reported by Ing and Bourne. ${ }^{51}$ Whether or not the DLEK patients will continue to suffer long-term attrition of endothelial cells similar to PK patients over the ensuing decades remains to be seen.

\section{Tectonically stable globe}

The Achilles' heel of PK is the fact that the vertical stromal wound of traditional full-thickness corneal grafting remains weak and unstable over years, if not decades, and never becomes as tectonically strong as the virgin nonincised tissue. The transient success of a PK graft yielding 20/20 vision for the patient can easily become the failure of a blind ruptured globe following mild blunt trauma, even years after the initial surgery. ${ }^{4-9}$ Indeed, even in the absence of blunt trauma, there is a reported $7.2 \%$ incidence of spontaneous wound dehiscence after the sutures are removed in PK patients, especially in the elderly age group of the Fuch's dystrophy population. ${ }^{4}$ The instability of the stromal wound is less dramatically evidenced by the shifts in spherical equivalent and corneal astigmatism seen after sutures are removed; yet this has real practical impact on the patient and physician as glasses and contacts are repeatedly changed. ${ }^{15,18,19,53}$ Finally, the surface epithelium following PK surgery is usually disrupted the day after surgery and it takes time for the surface epithelium to close, with up to $11 \%$ of patients with epithelial defects even 1 month after surgery. ${ }^{54}$ Such delays in the epithelial surface barrier leave the PK graft open to infection and melting early on in the postoperative course. With such significant risks for the long-term stability of the PK graft, it is small wonder that investigators have turned to a surgical lamellar solution.

In the initial reports by Melles and by Terry, the posterior grafts have adhered well, with no reports of dislocation. In the recent series by Terry, out of a total of 30 consecutive DLEK grafts done as of June 2002, he has seen one early graft dehiscence the day after surgery due to surgeon error. The graft was repositioned 1 week later 
with the use of an air bubble and the graft has remained stable with a clear cornea over the most recent follow-up time of 6 months for this patient (unpublished data). Although no blunt trauma has occurred to date in DLEK patients to test the strength of the wound, laboratory work with cadaver eyes immediately after DLEK surgery has shown the wounds and the grafts to be quite stable and safe, even with immediate blunt trauma. ${ }^{27}$ While this is expected, given the construction of the lamellar dissection and the scleral placement of the pocket incision, more work needs to be done in this area. What is certain is that the surface of the DLEK eye is safer in the early postoperative period than the PK eye. There have been no epithelial defects the day after surgery in any DLEK eye, and the surface topography is uniformly stable and smooth by the topography patterns seen at the 1 month checkup. ${ }^{28,30}$ The safety profile of DLEK with regard to surface infections, ulcerations, and certainly with regard to suture problems appears significantly better than the PK eye and fulfils this goal of endothelial replacement to a higher degree.

\section{Vision and the optically pure cornea}

PK can provide unmatched central stromal clarity and it is this feature that drives the preference for PK over LK in the surgical rehabilitation of anterior corneal disease. ${ }^{32}$ It is known that the optically deficient stromal interface of traditional anterior LK has often limited the final average vision to about $20 / 25$ or $20 / 30.55,56$ While we know that lamellar dissections by a microkeratome can be optically pure in LASIK surgery, the dissections in DLEK surgery are currently manual and may not yield the optical purity of a full-thickness graft. The visual results of Melles varied between 20/20 and 20/80 in his initial series at 6 months post-operative, but recent cases have shown vision of 20/25 at only 1 week post-operative with minimal astigmatism. ${ }^{29,42}$ In Terry and Ousley's ${ }^{30}$ initial series, the vision ranged between $20 / 30$ and 20/70. In their most recent series of 27 patients to reach the 3-month time gate, the vision has ranged between 20/25 and 20/200. However, in this elderly Fuch's population with prior intraocular surgery, the incidence of macular diseases such as age-related macular degeneration and cystoid macular oedema is high. Terry and Ousley have therefore attempted to determine the trend of the correlation between macular visual potential and the best spectacle-corrected visual acuity (BSCVA). Using the potential acuity meter (PAM) to measure macular potential in 12 of the first 15 patients, they found that the PAM test measures about one line better than the BSCVA. In the presence of excellent surface smoothness and corneal topography, the implication is that the manually dissected interface of the
DLEK cornea causes a loss of about one line of vision in the majority of patients. ${ }^{30}$ For example, if a DLEK patient's BSCVA is $20 / 40$, then the PAM test has shown $20 / 30$ potential vision; if the BSCVA is $20 / 25$, then the PAM test has shown a $20 / 20$ potential. In this elderly population with varied degrees of macular disease, greater numbers of DLEK surgery will be necessary to determine the validity and statistical significance of this finding.

Finally, similar correlation needs to be done regarding the macular potential of the age-matched PK patients and their BSCVA to determine if surface irregularity and high astigmatism cause a similar discrepancy between these visual tests with PK patients as we are finding with the DLEK patients.

\section{The future of DLEK surgery}

The early work with DLEK is indeed promising, but this remains a procedure in development and should still be done under the auspices of the surgeon's local Institutional Review Board (IRB). Gerrit Melles continues to work in the development of this surgery, and has devised new innovative techniques for endothelial replacement. He has published one case where the PLK incision has been shortened to just $5 \mathrm{~mm}$ in length, the donor tissue folded for insertion, and manipulated into place with an air bubble, and the resultant clear cornea yielded a vision of $20 / 25$ at just 1 week with only $1 \mathrm{D}$ of corneal astigmatism. ${ }^{42}$ Further patients need to have this modified surgery to determine the average endothelial cell survival after the trauma of graft folding. He has also published laboratory cadaver eye studies demonstrating the feasibility of pure Descemet's membrane transplantation with endothelial survival, but no patient to date has been treated with this radical technique. $^{43}$

The key to consistent visual results remains in the improvement of the DLEK stromal interface. The use of a microkeratome for the donor side of the interface is likely, and work continues on automation of the creation of the recipient pocket side of the interface. Mark Terry has founded the international Endothelial Keratoplasty Group (EKG) to study and improve this procedure with scientific rigour under IRB approval, and as more surgeons become involved with this surgery, the rate of technical advances should accelerate. ${ }^{30}$ Finally, the high-tech and expensive femtosecond laser holds great promise in this and other lamellar procedures, but extensive laboratory and histology work needs to be done, and regulatory issues with this laser need to be addressed, before widespread use of this device is feasible..$^{57-61}$ 


\section{Summary}

The future of surgical replacement of the endothelium requires loftier goals than what we have set in the past for PK. The corneal transplant surgeon needs to recognize that the short-term visual result of 20/20 may often only be obtained in traditional PK at the price of high astigmatism and inherent structural instability. With the advent of DLEK surgery, we have the opportunity to develop a technique that is not only safer and more predictable, but also promises the retention of the normal corneal topography with the associated absence of optical aberrations. If the interface of DLEK surgery can be further refined, this technique may very well be the ideal method for fulfilling the goals of endothelial replacement.

\section{References}

1 Chu W. The past 25 years in eye banking. Cornea 2000; 19(5): 754-765.

2 Borboli S, Colby K. Mechanisms of disease: Fuch's endothelial dystrophy. Ophthalmol Clin N Am 2002; 15: 17-25.

3 Sugar A, Sugar J. Techniques in penetrating keratoplasty: a quarter century of development. Cornea 2000; 19: 603-608.

4 Abou-Jaoude ES, Brooks M, Katz DG, Van Meter WS. Spontaneous wound dehiscence after removal of single continuous penetrating keratoplasty suture. Ophthalmology 2002; 109: 1291-1296.

5 Tseng SH, Lin SC, Chen FK. Traumatic wound dehiscence after penetrating keratoplasty: clinical features and outcome in 21 cases. Cornea 1999; 18: 553.

6 Perry HD, Donnenfeld ED. Expulsive choroidal hemorrhage following suture removal after penetrating keratoplasty. Am J Ophthalmol 1988; 103: 99-100.

7 Binder PS, Abel Jr R, Polack FM, Kaufman HE. Keratoplasty wound separations. Am J Ophthalmol 1975; 80: 109-115.

8 Agrawal V, Wagh M, Krishnamachary M, Rao GN, Gupta S. Traumatic wound dehiscence after penetrating keratoplasty. Cornea 1995; 14: 601-603.

9 Rehany U, Rumelt S. Ocular trauma following penetrating keratoplasty: incidence, outcome, and postoperative recommendations. Arch Ophthalmol 1998; 116: 1282-1286.

10 Akova YA, Onat M, Koc F, Nurozler A, Duman S. Microbial keratitis following penetrating keratoplasty. Ophthalmic Surg Lasers 1999; 30: 449.

11 Confino J, Brown SI. Bacterial endophthalmitis associated with exposed monofilament sutures following corneal transplantation. Am J Ophthalmol 1985; 99: 111.

12 Stechschulte SU, Azar DT. Complications after penetrating keratoplasty. Int Ophthalmol Clin 2000; 40: 27.

13 Jonas JB, Rank RM, Budde WM. Immunologic graft reactions after allogenic penetrating keratoplasty. Am J Ophthalmol 2002; 133: 437-443.

14 Belmont SC, Zimm JL, Storch RL, Draga A, Troutman RC. Astigmatism after penetrating keratoplasty using the Krumeich guided trephine system. Refract Corneal Surg 1993; 9: 250

15 Davis EA, Azar DT, Jacobs FM et al. Refractive and keratometric results after the triple procedure: experience with early and late suture removal. Ophthalmology 1998; 105: 624.

16 Gross RH, Poulsen EJ, Davitt S et al. Comparison of astigmatism after penetrating keratoplasty by experienced cornea surgeons and cornea fellows. Am J Ophthalmol 1997; 123: 636.

17 Reddy SC, Gupta S, Rao GN. Results of penetrating keratoplasty with cataract extraction and intraocular lens implantation in Fuchs' dystrophy. Indian J Ophthalmol 1987; 35: 161.

18 Riddle HK, Parker DA, Price FW. Management of postkeratoplasty astigmatism. Curr Opin Ophthalmol 1998; 9: 15.

19 Binder PS. The effect of suture removal on postkeratoplasty astigmatism. Am J Ophthalmol 1988; 105: 637.

20 Seitz B, Langenbucher A, Kus MM, Kuchle M, Naumann GO. Nonmechanical corneal trephination with the excimer laser improves outcome after penetrating keratoplasty. Ophthalmology 1999; 106: 1156.

21 Serdarevic ON, Renard GJ, Pouliquen Y. Randomized clinical trial of penetrating keratoplasty: before and after suture removal comparison of intraoperative and postoperative suture adjustment. Ophthalmology 1995; 102 1497.

22 Ruhswurm I, Scholz U, Pfleger T, Zehetmayer M, Hanselmayer G, Skorpik C. Three-year clinical outcome after penetrating keratoplasty for keratoconus with the guided trephine system. Am J Ophthalmol 1999; 127: 666.

23 Melles GR, Eggink FA, Lander F, Pels E, Rietveld FJ, Beekhuis WH et al. A surgical technique for posterior lamellar keratoplasty. Cornea 1998; 17: 618.

24 Melles GR, Rietveld FJ, Beekhuis WH, Binder PS. A technique to visualize corneal incision and lamellar dissection depth during surgery. Cornea 1999; 18: 80.

25 Melles GR, Lander F, Beekhuis WH, Remeijer L, Binder PS. Posterior lamellar keratoplasty for a case of pseudophakic bullous keratopathy. Am J Ophthalmol 1999; 127: 340.

26 Melles GRJ, Remeijer L, Geerards AJM, Beekhuis H. The future of lamellar keratoplasty. Curr Opin Ophthalmol 1999; 10: 253-259.

27 Terry MA, Ousley PJ. Endothelial replacement without surface corneal incisions or sutures: topography of the deep lamellar endothelial keratoplasty procedure. Cornea 2001; 20: $14-18$.

28 Terry MA, Ousley PJ. Deep lamellar endothelial keratoplasty in the first United States patients: early clinical results. Cornea 2001; 20: 239-243.

29 Melles GRJ, Lander F, van Dooren BTH, Pels E, Beekhuis WH. Preliminary clinical results of posterior lamellar keratoplasty through a sclerocorneal pocket incision. Ophthalmology 2000; 107: 1850-1857.

30 Terry MA, Ousley PJ. Replacing the endothelium without surface corneal incisions or sutures: first US clinical series with the Deep Lamellar Endothelial Keratoplasty Procedure. Ophthalmology 2003; 110: 755-764.

31 Terry MA, Ousley PJ. Replacing the endothelium without surface corneal incisions or sutures: spherical equivalent refractive results in the first U.S. DLEK patients. Invest Ophthalmol Vis Sci 2002; 43: 1002 (ARVO Abstract \#4168).

32 Terry MA. The evolution of lamellar grafting techniques over twenty-five years. Cornea 2000; 19: 611.

33 von Hippel A. Eine neue Methode der Hornhaut transplantation. Graefes Arch Ophthalmol 1888; 34: 108. 
34 Jones DT, Culbertson WW. Endothelial lamellar keratoplasty (ELK) [ARVO Abstract]. Invest Ophthalmol Vis Sci 1998; 39(4): S76 (Abstract no. 342).

35 Busin M, Arffa RC, Sebastiani A. Endokeratoplasty as an alternative to penetrating keratoplasty for the surgical treatment of diseased endothelium: initial results. Ophthalmology 2000; 107: 2077-2082.

36 Ehlers N, Ehlers H, Hjortdal J, Moller-Pedersen T. Grafting of the posterior cornea: description of a new technique with 12-month clinical results. Acta Ophthalmol Scand 2000; 78: 543-546.

37 Silk W, Gupta P, Stevens G. Endothelial lamellar keratoplasty: ten patient series report. ARVO abstract, Ft Lauderdale, FL, 2002.

38 Azar DT, Jain S, Sambursky R, Strauss L. Microkeratomeassisted posterior keratoplasty. J Cataract Refract Surg 2001; 27: 353-356.

39 Sandeep J, Azar DT. New lamellar keratoplasty techniques: posterior keratoplasty and deep lamellar keratoplasty. Curr Opin Ophthalmol 2001; 12: 262-268.

40 Li L, Ellis KR, Behrens A, Sweet PM, Chuck RS. A laboratory model for microkeratome-assisted posterior lamellar keratoplasty utilizing a running graft suture and a sutureless hinged flap. Cornea 2002; 21: 192-195.

41 Ko W, Freuh B, Shield C, Costello M, Feldman S. Experimental posterior lamellar transplantation of the rabbit cornea. Invest Ophthalmol Vis Sci 1993; 34: 1102 (ARVO abstract).

42 Melles GR, Lander F, Nieuwendaal C. Sutureless, posterior lamellar keratoplasty: a case report of a modified technique. Cornea 2002; 21: 325-327.

43 Melles GR, Lander F, Rietveld FJR. Transplantation of descemet's membrane carrying viable endothelium through a small scleral incision. Cornea 2002; 21: 415-418.

44 Terry MA. Endothelial replacement: the Limbal Pocket approach. Ophthalmol Clin N Am 2003; 16: 103-112.

45 Terry MA, and Ousley PJ. Corneal Endothelial transplantation: advances in the surgical management of endothelial dysfunction. Contemp Ophthalmol 2002 (in press).

46 Terry MA, Ousley PJ. The new triple procedure: first world wide patients with DLEK combined with Phaco/IOL surgery. American Academy of Ophthalmology Video Library, Annual Meeting, October 2002.

47 Pineros OE, Cohen EJ, Rapuano CJ, Laibson PR. Triple vs nonsimultaneous procedures in Fuchs' dystrophy and cataract. Arch Ophthalmol 1996; 114: 525.
48 Wilson SE, Klyce SD. Quantitative descriptors of corneal topography: a clinical study. Arch Ophthalmol 1991; 109: 349.

49 Duran JA, Malvar A, Diez E. Corneal dioptric power after penetrating keratoplasty. Br J Ophthalmol 1989; 73: 657.

50 Isager P, Hjortdal JO, Ehlers N. Stability of graft refractive power after penetrating keratoplasty. Acta Ophthalmol Scand 2000; 78: 623 .

51 Bourne WM. Cellular changes in transplanted human corneas. Cornea 2001; 20: 560.

52 Ing JJ, Ing HH, Nelson LR, Hodge DO, Bourne WM. Ten-year postoperative results of penetrating keratoplasty. Ophthalmology 1998; 105: 1855.

53 Price FW, Whitson WE, Marks RG. Progression of visual acuity after penetrating keratoplasty. Ophthalmology 1991; 98: 1177.

54 Machado RAM, Mannis MJ, Mandel HA, Feiz V, Schwab IR, Wang $\mathrm{W}$ et al. The relationship between first postoperative day epithelial status and eventual health of the ocular surface in penetrating keratoplasty. Cornea 2002; 21: 574-577.

55 Benson W, Goosey J. Lamellar keratoplasty. In: Krachmer J, Mannis M, Holland E (eds). Cornea: Surgery of the Cornea and Conjunctiva. Mosby-Year Book, Inc: St Louis, 1997, pp 1833-1842.

56 Rich LF. Expanding the scope of lamellar keratoplasty. Trans Am Ophthalmol Soc 1999; 97: 771.

57 Sletten KR, Yen KG, Sayegh S, Loesel F, Eckhoff C, Horvath $\mathrm{C}$ et al. An in vivo model of femtosecond laser intrastromal refractive surgery. Ophthalmic Surg Lasers 1999; 30: 742-749.

58 Lubatschowski H, Maatz G, Heisterkamp A, Hetzel U, Drommer W, Welling H et al. Application of ultrashort laser pulses for intrastromal refractive surgery. Graefes Arch Clin Exp Ophthalmol 2000; 238: 33.

59 Krueger RR, Juhasz T, Gualano A, Marchi V. The picosecond laser for nonmechanical laser in situ keratomileusis. J Refract Surg 1998; 14: 467.

60 Krueger RR, Marchi V, Gualano A, Juhasz T, Speaker M, Suarez C. Clinical analysis of the neodymium: YLF picosecond laser as a microkeratome for laser in situ keratomileusis: partially sighted eye study. J Cataract Refract Surg 1998; 24: 1434.

61 Kurtz RM, Horvath C, Liu HH, Krueger RR, Juhasz T. Lamellar refractive surgery with scanned intrastromal picosecond and femtosecond laser pulses in animal eyes. J Refract Surg 1998; 14: 541. 